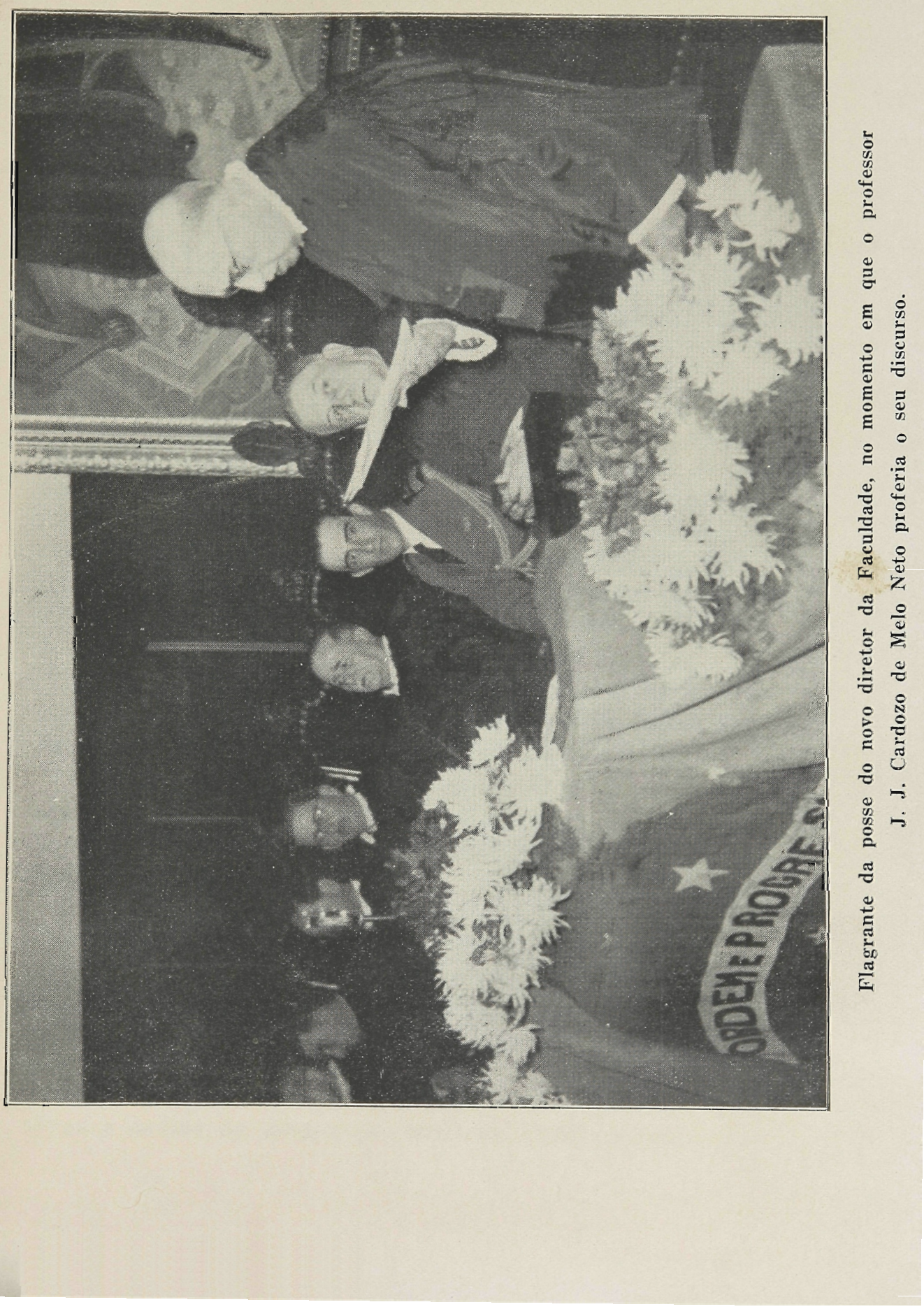


FACULDADE DE DIREITO

\section{Posse do novo diretor da Faculdade, professor J. J. Cardozo de Melo Neto}

Realizou-se, a 16 de junho do corrente ano, ás 16 horas, na sala "João Mendes Júnior", a solenidade da posse do novo diretor da Faculdade de Direito da Universidade de São Paulo, professor J. J. Cardozo de Melo Neto. Presidiu à cerimônia o professor Rubiấo MeIra, reitor da Universidade, achando-se presentes os membros da Congregação da Faculdade, altas autoridades do Estado, representantes do govêrno de S. Paulo, além da numerosa assistência constituida de senhoras, cavalheiros e corpo discente.

Lido o termo de posse pelo secretário-geral da Universidade, assinou-o o professor J. J. Cardozo de Melo Neto, ocasião em que recebia a salva de palmas da assistencia.

Em seguida, o reitor da Universidade usou da palavra, saudando o diretor que acabava de tomar posse na importante investidura. Foi o que segue, o discurso do professor Rubião MeIra:

"Entre as conquistas mais elevadas e mais sublimes que podem curvar o espirito do homem, cercando sua atividade de fóros de nobreza e seu tirocínio profissional de galhardia de superioridade, está, sem dúvida, a do professorado superior, encarregado da suprema missão de evangelizar pelo caminho do bem a mocidade de sua terra, criando energias vivas e sadias de uma raça, forjando continuadas aspira- 
ções de amôr à justiça e à liberdade, robustecendo a inteligência e levantando o nivel moral e cultural, que representam o grau de poderio de uma nação, mesmo em época como esta que o mundo atravessa, de ferro, de aço e de sangue, mas em que ainda é o espirito do direito quem governa, é a alma da razão que ha de sobrepairar no julgamento final da história.

Domina o ápice da hierarquia das ambições individuais, a centelha luminosa da cadeira professoral. E' o professor das Universidades quem nas sociedades reune maior soma de majestade, a majestade imponente do cultivo da ciência, a majestade elegante da sabedoria, a majestade soberana do civismo e do amôr à patria. Não é a superioridade balofa da ignorância nem da inconciência, mas a da verdade dos conhecimentos humanos, a da justeza do saber, ou dignidade do valor cultural. E' essa a sua fôrça, é esse o padrão de sua glória, esse o destino de sua vida.

Nesse desígnio se compendia a formação moral da juventude, a demonstração de erros e a aprendizagem das certezas, o aparelhamento intelectual para as virtudes da existência, a coordenação das fôrças do espirito para as pugnas do bem, em defesa da coletividade, amparando seus direitos e reforçando sua fé, reunindo as energias pạra as cruzadas beneméritas em prol da humanidade, ungindo com o trabalho as suas aspirações e seus desejos.

$\mathrm{Na}$ escala social o professor universitário tem em mãos irresistivel atração e invenciveis fôrças - atração que o torna merecedor de homenagens constantes, porque tira de seu cérebro os lumes do saber e afaga a mentalidade juvenil, fôrças, que são essas mesmas que se reunem no condensamento de ideais para a realização de conquistas sublimes do espírito humano e essas são as da civilização, essas são da pureza de fé e da grandeza pátrias, essas são as da liberdade, as do direito, as da justiça, as da saniedade física e mental, as da beleza da vida e a arquitetura sadia dos templos onde se prègam as lições de patriotismo e magnitude 
das raças; essas são as da clarividência da luz projetada sôbre as paginas da história.

Os atributos conferidos ao professor universitário vão além do cultivo da ciência - seus deveres contêm a maior soma de responsabilidades porque vêm se fazer sentir sôbre a inteligência dos moços já preparados e muitas vezes mal preparados para receberem as sementes do saber. A eles compete dirigir a mentalidade da juventude, criar-lhe atmosfera benfazeja, destruindo idéias malsãs, princípios perigosos, dar-lhes as noções sublimadas do amor à patria, levantar em seu coração os estímulos permanentes para a dedicação a sua carreira profissional, impregnar as dobras de seu cérebro com as lições maiores da sabedoria humana, que se reunem nos principios sagrados do evangelho, e nas páginas rutilantes dos textos cristãos.

A sua função é dupla e encantadora - mas é a moral a maior delas, a mais necessária, a indispensavel para a formação de nossa mocidade, justamente neste trecho da vida humana em que nada se percebe diante dos olhos senão o rubor do sangue derramado, senão o entrechocar de ferros destruidores, a ruina, a devastação, a miséria, a morte. E' imprescindivel a formação espiritual de nossa juventude, preparando-a forte para os embates da vida futura. A atual geração vai entrar em contato com as remodelações dos principios que governam o mundo. A guerra européia traz os toques de reivindicação e de imposições novas no conceito dos povos. Mas é só a destruição dos regimes antigos, é a fundação de outros, com bases diferentes, diversas. O que a revolução francesa praticou em o seculo 18, dispondo a liberdade, a igualdade e a fraternidade, o desfêcho dessa luta que ensanguenta o solo da velha Europa, vai trazer modificações sensiveis na orientação das gentes. E' o revolvimento total de idéias antigas, subtraidas pelos que empolgam o pensamento humano, neste instante. E' necessário preparar a mocidade, darlhe noções filosóficas indispensaveis à apreciação do novo regime, desse regime a que ela vai dar todas suas energias, 
todo seu contingente entusiástico e nobre. O professor universitário está encarregado de implantar no espírito dos moços o amor ao trabalho e à pátria, dar-lhes a fôrça da cordialidade e união para que enfrentem, com sobranceria a situação nova, impregnar seu ânimo do valor do homem nas conquistas do direito.

A essa geração está confiado o futuro da nação, nesse momento tempestuoso de idéias que caem e outras que se levantam, de princípios destruidos e outros que superam, mas têm que guardar puros os sentimentos de justiça para poder vencer, as manifestações de liberdade para atingir ao verdadeiro desejo dos povos. Essas as suas fôrças. E é, justamente aqui, na velha Faculdade de Direito, que vão se encontrar os batalhadores da cruzada santa de remodelação, porque, no Brasil, daquí partiram os arautos de todas as liberdades públicas, aquí se forjaram os pioneiros iluminados de todas as conquistas nacionais, em todos os tempos, em todas as épocas. Ao professor de Direito cabe essa prerrogativa modelar, é em suas mãos que reside o poder formador da espiritualidade brasileira. E' a sua congregação que tem o poderio maior de ilustrar as inteligências jovens, que vêm beber o leite do saber, mas receber tambem as noções de civismo, os conhecimentos da fôrça mental, os princípios filosóficos indispensaveis á sua cultura.

Andou acertado, o sr. Interventor Federal, colocandovos, sr. professor Cardozo de Melo Neto, à frente do movimento condensador de energias e de sabedoria, pondo-vos como Diretor da Faculdade de Direito da Universidade de S. Paulo. Vossa personalidade destaca-se como a de homem af eito a lutas e à administração. Vosso passado é uma garantia, e vossa atitude sempre foi pautada pelo rigorismo absoluto do cumprimento do dever. Professor notavel, cujos ensinamentos atraem a atenção, parlamentar de escól, administrador cheio de idéias sãs e princípios dignos, vosso nome é uma bandeira, que coordena energias e impõe respeito. Nas vicissitudes de vossa vida publica guardastes sempre o amor à vossa catedra. Nos momentos mesmo em 
que vossa atividade impossibilitou a presença nesta casa, daquí não tirastes as vistas, e para ela correstes, cheio de dignidade e valor, nas horas amargas que a política vos deu. E' que ela foi conquistada pelos vossos estudos e pelas noites de vigilia, é que ela representa em vosso espírito o maior triunfo de vossa vida, porque perpetua e não sujeita a injunções de qualquer ordem. Esse, o valor da cátedra, essa a grandeza do professorado. Em contato com a mocidade recebeis sempre os estímulos de nobreza, em presença de vossos pares estais sempre na família do trabalho. Hoje sois o Diretor da Faculdade de Direito, e ocupais a cátedra máxima por onde passaram os luminares da ciência jurídica. Voltai vossos olhos para essa galeria e sentis, em vosso ânimo, nascerem novas energias e crescerem novas fôrças, capazes de vos garantir a mesma benemerência, a mesma imponência de sabedoria e valor. Cultivai o amor às tradições desta Casa, berço de liberdades pátrias, orientadoras da justiça e do direito. Nada vos falta para atingir ao apogeu da consagração. $\mathrm{E}$, esta é a maior que vosso espirito possa desejar. As demais passam como o tempo e se somem com o tumultuar de paixões, mas no cargo elevado a que acabais de subir, pelo vosso merecimento, permanecerá vossa ação sempre impressa, e para sempre, na alma dos presentes como na dos vindouros.

Recebei sr. dr. Cardozo de Melo Neto os protestos de cordialidade e alta simpatia, grande entusiasmo e fervor de admiração, a quem procura cooperar para a grandeza do ensino em S. Paulo, batalhando tambem, por isso, pela majestade cultural do Brasil".

Em nome da Congregação da Faculdade, falou o professor Gabriel de Rezende Filho, vice-diretor e catedrático de direito judiciário civil, cujas palavras foram as seguintes:

"A nossa Casa está hoje em festas, toda engalanada, para vos fazer sentir, em meio dos vossos colegas de magistério e dos vossos discípulos, a par dos vossos amigos, que enchem esta sala e tornam esplêndida esta assembléia, o quanto lhe 
foi grata a acertada escolha do vosso nome para o alto cargo de Diretor da Faculdade de Direito.

Cabe-me o dever de saudar-vos em nome da Congregação, e as singelas palavras, que vou proferir, são as palavras de um vosso colega, filho desta Casa tradicional, como tambem o sois, irmanados ambos no mesmo afeto por ela, comungando idênticos ideais, que aqui nos fez companheiros na carreira do professorado por amor a este Templo centenário.

Ao trazer os louvores a que tendes direito, não vos trago absolutamente o incensário da lisonja, pois pretendo apenas realçar, como de justiça, as virtudes de vossa vida, toda ela dedicada á causa do Direito, mesmo nos postos diversos que desempenhastes fóra do nosso círculo.

Entre outros atos inequívocos, que bem traduzem o empenho do atual Govêrno de colocar á frente dos serviços públicos homens competentes e dedicados, afim de serem providas eficazmente as necessidades do nosso Estado, basta a eleição do vosso nome prestigioso para atestar o cuidado com que procurou, dentre os valores que integram esta Congregação, o professor, de sua confiança sem dúvida, mas que estava naturalmente indicado para Diretor da Faculdade, pelos muitos títulos de que é portador.

A vossa formosa cultura jurídica, a vossa experiência, o vosso passado de honradez, o vosso patriotismo, a vossa reputação ilibada - virtudes que confirmastes sempre em toda a vossa atividade pública dentro desta Casa e nos vários encargos que assumistes na política e na administração tudo isso tem sido motivo sobêjo da vossa brilhante carreira sempre ascendente e constitúe, do mesmo passo, o penhor do eficiente desempenho que dareis á vossa nova e árdua missão.

Esta Casa foi sempre um esplêndido viveiro de nobres espíritos, que honram o ensino superior: sobram aqui dedicações e competências, mas, felizmente, aqui minguam as competições pessoais.

De todos nós, éreis, sr. professor Cardozo de Melo Neto, o destinado a reger a Faculdade pela vossa qualidade de decâno e pelos vossos incontestaveis méritos. 
Culminais, assim, no magistério superior da República.

E a vossa investidura, si a nós enche de intimo júbilo, aplaudida será tambem pelo corpo discente da Escola, por esta mocidade entusiasta e generosa, que enche os nossos corredores e arcadas, no bulício de uma colmeia infatigavel, e que de ha muito se habituou a ver na vossa individualidade um dos mestres que comungam sinceramente com as suas legítimas aspirações, sempre disposto a orientá-la no bom caminho dos estudos e do amor da pátria.

A vossa carreira de professor, que já vai por mais de quatro lustros, tem sido, na realidade, uma bela página oferecida á meditação dos moços e um exemplo que enriquece o patrimônio moral de S. Paulo.

Figurais entre os nossos grandes mestres, por que tendes sido dedicado e eficiente no cumprimento dos vossos deveres e vigilante na defesa das tradições impereciveis da Faculdade e na mantença e aperfeiçoamento da civilização de nossa terra.

Pela sua larga projeção dentro e fóra desta Casa, a vossa vida constitue um traço firme de uma personalidade de escól, onde se reunem harmonicamente os mais delicados sentimentos, o talento, a cultura e o civismo.

E como se reflete ela, afinal, na nossa querida Faculdade!

Orgulhamo-nos todos de seu passado glorioso, das gerações sucessivas que ha mais de cem anos vêm formando o espirito á sombra agazalhadora de suas arcadas, e enriquecendo a inteligência no trato de seus mestres e o carater ao bafêjo de suas nobilíssimas tradições!

Em que pesem ás arremetidas dos pessimistas e desiludidos, a conciência jurídica nacional é, indubitavelmente, um dos mais valiosos elementos de integração do país.

Em época nenhuma de nossa história tivemos tanta necessidade das ciências jurídicas como hoje, quando encaramos, inquietos, o nosso porvir, ameaçados pelas incertezas e sombrios prognósticos oriundos da guerra que ensanguenta as maiores nações do mundo. 
Cumpre-nos, por isso, servir a Faculdade com carinho redobrado, para sermos dignos sucessores dos nossos antepassados, pregando os ideais, que foram seus tambem, de fé ardente na boa causa do Direito, que não deve esmaecer, pena de sossobrar irremediavelmente a nossa civilização.

Que esse amor pelas tradições acadêmicas e que esse ideal comum, que a todos nos anima e conforta nestas horas trágicas da humanidade, sejam mantidos e realçados com toda a energia, porque daí só advirão benefícios para o fortalecimento das instituições e para o império da ordem, sem a qual é impossivel o trabalho profícuo e a prosperidade geral.

Exaltêmo-la, reafirmando os nossos propósitos de bem serví-la, pondo á sua disposição a nossa inteligência e todas as nossas energias!

Só assim, pelo nosso carinho, hoje que somos responsaveis pelos seus destinos, e pelo carinho desta mocidade, que aquí aprende a conhecer e estimar o Direito, e que, amanhã pelos seus lídimos representantes, continuará na fâina de cultuá-lo, ensinando-o ás gerações porvindouras, só assim a Faculdade não desmerecerá do alto conceito em que sempre foi tida, como grande centro cultural do país.

Um novo periodo de sua vida abre-se hoje, sr. professor Cardozo de Melo Neto, ao assumirdes solenemente a sua direção.

Podeis contar conosco em todas as horas para o bem da Faculdade, pois depositamos inteira confiança no vosso alto descortino e na vossa ação realizadora.

Prevemos também, mercê do vosso passado, o ardor com que defendereis o bom nome e o prestígio desta Casa e o empenho na estrita observância do programa que, por certo, já traçastes de vossa administração.

Nestas palavras descoloridas, ao passar-vos o exercício do cargo de Diretor da Faculdade, desejei apenas externar, em meu nome e no dos meus colegas, a nossa íntima satisfação pela vossa investidura e formular os mais efusivos votos 
para que realizeis obra construtiva, digna desta Casa, que é legítimo orgulho de Piratininga e do Brazil."

Em nome dos alunos do curso de bacharelado, discursou o acadêmico Ru Homem de Melo Lacerda, exalçando o valor do mestre que acabava de assumir a direção da Faculdade.

Levantou-se, a seguir, o professor J. J. Cardozo de Melo NETo que, entre continuadas ovações e aplausos, proferiu a sua oração de compromisso e agradecimento:

"Investido pelo honrado governo do Estado, no cargo de diretor da Faculdade de Direito, constitue para mim motivo de particular desvanecimento tomar posse perante $\mathrm{v}$. exa., sr. professor Rubião Meira, grande clínico e brilhante professor de Medicina, a quem me ligam de ha muitos anos os mais afetuosos laços de amizade; assim como receber a direção da nossa tradicional Academia de v. exa., sr. professor Soares de Faria, a quem de público rendo as homenagens devidas pelos serviços que, com dedicação e competência, pôde á Faculdade prestar.

Cumpre-me, tambem, deixar expressos meus agradecimentos, partidos do coração, pelas vossas palavras, sr. prof. Gabriel de Rezende Filho, - lídimo representante da Congregaão que, nesta Casa, com ilustre e exemplar compostura, mantém o facho da quarta geração de professores de Direito.

Não quero esconder a emoção que de mim se apodera, neste momento.

Filho desta casa, tendo aprendido a querê-la através de meu pai, de meus tios e da memoria de meu avô, para aqui voltei, 12 anos depois, como o último dos professores, na idade e na competência. Aquí estou ha cerca de 24 anos, afastado apenas durante as interrupções das investiduras de representante de São Paulo na Asembléia Nacional Constituinte e no Grovêrno do Estado. Aquí estou realizando sem desfalecimento de um dia, e com entranhado amor, a mais alta aspiração da minha mocidade. Feliz, porque a conciência 
diz-me ter feito tudo quanto em mim cabia para suportar o julgamento irrecorrivel daqueles que, mortos, vivem eternamente na memória e na saudade desta casa, e dos que, vivos, dia a dia acompanham a dedicação de quem, não tendo forças para servi-la quanto deve, ao menos trabalha quanto pode para guardar intacta a tradição de respeito ao Direito, de estudo orientado no sentido do interesse social, e de civismo, que formam a propria substância moral da Casa que, ha mais de um século, vê passar, por suas arcadas, a principio, os Ministros de Deus, e, depois, aqueles que, por sucessivas gerações, se têm penetrado da magnitude do Direito, com a manifestação mais viva da existência e onipotência divina.

Aquí estou, meus eminentes colegas da Congregação, já agora o mais antigo dentre vós, e só por isso não preterindo a ninguem, para coordenar vossas energias em beneficio da formação da mentalidade jurídica da mocidade, da sua diretriz moral e cívica, que uma e outra constituem um todo indissoluvel, porque a noção do Direito é incompreensivel fóra da regra moral e do culto da Pátria.

Aquí estou para pôr á prova a nossa amizade que jamais deve esmorecer, como homens que o Destino uniu pela vocação, e somente a morte deverá separar.

Aquí estou, moços de hoje, com a mesma fé dos moços de hontem orgulhoso e desvanecido por me ser dado acompanhar, orientando, a quadra decisiva da vossa juventude - aquela que deixará uma marca indelevel no vosso espirito, e decidirá o futuro, - aquela que estais vivendo sob as arcadas da Academia, materialmente renovadas, mas, ontem como hoje, implantadas no mesmo chão em que Rui aprendeu e José Bonifácio, o moço, ensinou.

Evoco, nesta hora tão grata ao meu coração quão cheia de responsabilidades, as figuras solares daqueles que, tendo dirigido a Academia, somente vivem no culto da nossa saudade. 
Desde o primeiro diretor do modesto curso juridico do Convento de São Francisco, até aquele a cuja energia se deve a renovação desta casa.

Desde Arouche Rendon até Alcantara Machado, insignes exemplares da raça, paulistas ambos que o Brasil reverencia porque bem o serviram.

Simbolos para a geração presente. Exemplos e incentivos para mim que hoje recebo e prometo transmiti-la intacta, a secular herança de cumprimento do dever, da honra e dignidade dos diretores da Faculdade e Direito de São Paulo". 